\title{
PENGARUH KEMASAN TERHADAP MINAT BELI MASYARAKAT DENGAN KUALITAS SEBAGAI VARIABEL MEDIASI PADA PRODUK "LEGIT"
}

\author{
Billy Ivanko \\ Program Studi Magister Manajemen Universitas Tarumanagara \\ billy.ivanko@gmail.com \\ Hetty Karunia Tunjungsari \\ Program Studi Magister Manajemen Universitas Tarumanagara
}

\begin{abstract}
The purpose of this research was to analyze the effect of packaging toward purchase intention with quality of the product as a mediation variable for Micro, Small, and Medium Scale Business "Legit" Product. This research used descriptive quantitative methods. The method of data collection were primary and secondary data. The population of this research is the entire Indonesia population of 2016 (257.912.349 peoples). This study used non-probability sampling technique by taking purposive sampling. This study used simple linear regression and multiple linear regression with instrument test, a classic assumption (normality, multicollinearity, and heteroscedasticity), model test (adjusted R2, T test and F test), Causal Steps and Bobel Test to checked the validity of the hypothesis. Based on the results of the study, it was found that the packaging has a significant effect on the purchase intention of the Legit's product, the packaging has a significant effect towards the quality of the Legit's product and the packaging has a significant effect towards the purchase intention of the Legit's product with the quality of the product as a mediated variable.
\end{abstract}

Abstrak: Tujuan dari penelitian ini adalah untuk mengetahui pengaruh kemasan terhadap minat beli masyarakat dengan kualitas sebagai variabel mediasi pada produk Usaha Mikro, Kecil, dan Menengah "Legit". Penelitian ini menggunakan metode deskriptif kuantitatif. Metode pengumpulan data dilakukan dengan menggunakan data primer dan sekunder. Populasi penelitian ini adalah seluruh masyarakat Indonesia tahun 2016 (257.912.349 penduduk). Penelitian ini menggunakan regresi linear sederhana dan berganda, dengan uji instrumen, asumsi klasik (uji normalitas, multikolinieritas dan heterokedastisitas), uji model (adjusted $\mathrm{R}^{2}$, uji $\mathrm{T}$, ujiF), pengujian Causal Step, dan pengujian Sobel Test untuk menguji kebenaran hipotesis penelitian. Hasil dari penelitian ini adalah bahwa kemasan memiliki pengaruh yang signifikan terhadap minat beli produk merek Legit, kemasan memiliki pengaruh yang signifikan terhadap kualitas produk merek Legit, kemasan memiliki pengaruh yang signifikan terhadap minat beli yang dimediasi oleh kualitas produk merek Legit.

Keyword: Packaging, Quality, Purchase Intention

\section{PENDAHULUAN}

\section{Latar Belakang}

Indonesia memiliki banyak sektor industri yang dapat dikembangkan khususnya pada makanan dan minuman. Berbagai jenis produk yang dihasilkan oleh para pelaku bisnis Usaha Mikro, Kecil dan Menengah juga tidak kalah dari pengusaha besar. Kondisi persaingan pasar di Indonesia yang cukup kompetitif menjadi aspek yang tidak lepas dari perhatian, mereka harus saling bersaing untuk mampu menjadi yang diminati di pasar. Namun ada satu aspek yaitu kemasan yang menjadi salah satu masalah yang saat ini sedang dihadapi oleh pelaku usaha di Indonesia. Suhendra (2009) menyatakan saat ini pelaku UMKM di Indonesia berpikir bahwa produk UMKM tidak harus memiliki kemasan bagus selain itu UMKM juga berpikir bahwa kemasan bagus hanya perlu diterapkan oleh industri besar. 
Polyakova (2013) menyatakan bahwa salah satu alat marketing yang sangat popular dan penting yaitu kemasan serta desain dari kemasan tersebut. Melalui kemasan suatu pengusaha dapat membedakan diri mereka satu sama lain. Kottler dan Amstrong (2012) kemasan melibatkan kegiatan mendesain dan memproduksi, untuk melindungi produk. Kemasan selalu melibatkan design agar pesan produk tersampaikan kepada konsumen, fungsi kemasan sendiri saat ini selain untuk melindungi produk juga berfungsi sebagai media pemasaran yang jitu. Kok (2015) menemukan kemasan memiliki pengaruh positif terhadap minat pembelian, kemudian warna dan bentuk memiliki peran penting dan krusial dalam memperkenalkan merek pada konsumen. Selain dari kemasan, kualitas pun juga merupakan salah satu faktor penting dalam menarik minat beli konsumen terhadap suatu produk. Produk yang baik adalah produk yang terjaga secara kualitas sejak dibuat hingga sampai di tangan konsumen.

Berdasarkan latar belakang diatas, maka peneliti tertarik untuk melakukan penelitian mengenai "Pengaruh Kemasan Terhadap Minat Beli Masyarakat dengan Kualitas Sebagai Variabel Mediasi pada Produk "Legit"”.

\section{Tujuan Penelitian}

Berdasarkan latar belakang diatas, maka tujuan dari penelitian ini adalah:

- Mengetahui dan menjelaskan pengaruh kemasan produk secara langsung terhadap minat beli produk kerupuk ikan tenggiri merek Legit.

- Mengetahui dan menjelaskan pengaruh kemasan produk terhadap kualitas produk kerupuk ikan tenggiri merek Legit.

- Mengetahui dan menjelaskan pengaruh kemasan produk terhadap minat beli produk kerupuk ikan tenggiri merek Legit dengan kualitas produk sebagai variabel mediasi.

\section{TINJAUAN PUSTAKA}

\section{Kemasan, Kualitas, Minat beli}

Menurut Naik (2015), kemasan telah menjadi sarana vital untuk membedakan suatu barang dengan barang lainnya dan sebagai sarana untuk menarik perhatian pelanggan. Kemasan telah menjadi aspek penting dalam pemasaran dan diperlakukan sebagai salah satu faktor paling berpengaruh dalam keputusan pembelian konsumen pada saat pembelian suatu produk. Sebagai salah satu alat pemasaran kemasan memiliki 4 (empat) fungsi yaitu self service, consumer offluence, company and brand image, serta inovational opportunity.

Menurut Kotler dan Amstrong (2008) kemampuan sebuah produk dalam memperagakan fungsinya, hal itu termasuk keseluruhan durabilitas, reliabilitas, ketepatan, kemudahan pengoperasian dan reparasi produk juga atribut produk lainnya. Orville et al (2005) menyatakan dimensi kualitas terdiri atas kinerja, daya tahan, kesesuaian dengan spesifikasi, fitur, reliabilitas, estetika dan kesan kualitas.

Menurut Farooq (2015), keputusan pembelian konsumen seringkali sangat kompleks, sangat penting bagi manajer untuk mengukur kepuasan pelanggan. Minat pembelian juga digunakan sebagai alat yang paling efektif saat kita mencoba memprediksi proses pembelian.

\section{Kerangka Pemikiran}

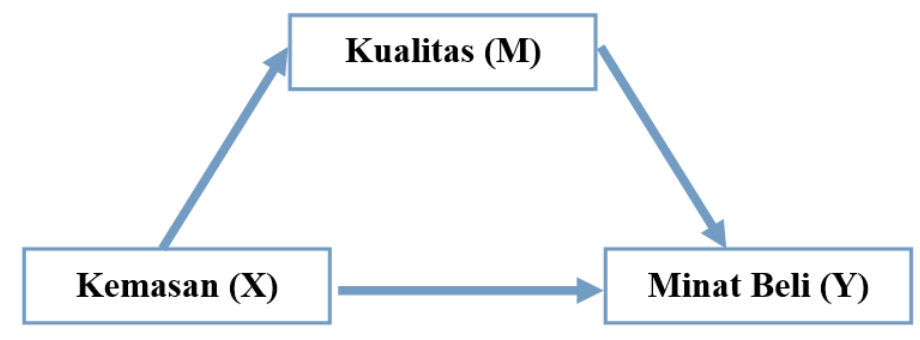




\section{Gambar \\ Kerangka Pemikiran Peneliti}

\section{Hipotesis Pemikiran}

- H1: Diduga kemasan produk berpengaruh positif dan signifikan terhadap minat beli produk Legit.

- H2: Diduga kemasan produk berpengaruh positif dan signifikan terhadap kualitas produk Legit.

- H3: Diduga kemasan produk berpengaruh positif dan signifikan terhadap minat beli produk Legit dengan kualitas produk sebagai variabel mediasi.

\section{Metode Penelitian}

Penelitian ini menggunakan metode penelitian deskriptif dengan pendekatan kuantitatif yang dilaksanakan dengan periode penelitian dari Januari - November 2018. Objek penelitian ini yaitu pengaruh kemasan terhadap minat beli masyarakat dengan kualitas sebagai variabel mediasi pada produk Legit" yaitu kerupuk olahan ikan tenggiri yang dikembangkan oleh mahasiswa Universitas Tarumanagara dengan merek Legit. Dimana sampel diambil dari total seluruh masyarakat Indonesia tahun 2016 dengan disebarkan kuesioner terhadap 500 di 5 wilayah Kota Besar yang ada di Indonesia yaitu Medan, Jakarta, Bandung, Semarang dan Surabaya. Jenis data yang digunakan adalah data primer menggunakan kuisioner dengan skala likert (Skala 6) serta data skunder untuk kemasan, kualitas dan minat beli. Variabel dalam penelitian ini terdiri atas variabel bebas yaitu kemasan, variabel mediasi yaitu kualitas dan varibel terikat yaitu minat beli.

Sebelum dilakukan analisis, data yang telah dikumpulkan harus diuji terlebih dahulu menggunakan program SPSS (Statistical Package for Social Science) versi 25.0 Tahun 2017 agar mendapat hasil yang lebih efisien. Untuk itu, maka dilakukan beberapa pengujian, yaitu:

- Uji Instrumen

Terdiri atas uji validitas dan uji reliabilitas.

- Uji Asumsi Klasik

Terdiri atas uji normalitas, uji heterokedastisitas, uji linearitas dan uji multikolinieritas.

- Uji Model

Terdiri atas uji Koefisien Determinasi/R ${ }^{2,}$ uji T, dan Uji F.

- Pengujian Causal Step

Suatu variabel disebut mediator jika variabel tersebut ikut mempengaruhi hubungan antara variabel prediktor (independen) dan kriterion (dependen).

- Pengujian Sobel Test

Uji Sobel dilakukan dengan cara menguji kekuatan pengaruh tidak langsung X ke Y

\section{Hasil Penelitian}

- Uji Statistik Deskriptif

\begin{tabular}{|c|c|c|c|c|c|}
\hline Variabel & $\mathbf{N}$ & Minimum & Maximum & Mean & Std. Deviation \\
\hline Kemasan & 500 & 2,80 & 5,50 & 3,9510 & 0,58685 \\
\hline Kualitas & 500 & 2,40 & 6,00 & 5,1916 & 0,71222 \\
\hline Minat Beli & 500 & 3,50 & 6,00 & 5,2004 & 0,64946 \\
\hline
\end{tabular}

- $\quad$ Uji Distribusi Frekuensi

$>$ Tanggapan Responden terhadap Kemasan 
Tanggapan responden terhadap pernyataan secara rata - rata cukup setuju, hal ini dibuktikan nilai mean yang diperoleh pada setiap pernyaataan berada pada interval rata - rata 3,49 $\leq \mathrm{x}<4,32$ yaitu di angka 3,94. Kemasan yang diharapkan oleh konsumen adalah kemasan dengan adanya informasi produk yang jelas dan rinci.

\section{$>\quad$ Tanggapan Responden terhadap Kualitas}

Tanggapan responden terhadap pernyataan secara rata - rata sangat setuju, hal ini dibuktikan nilai mean yang diperoleh pada setiap pernyaataan berada pada interval rata - rata 5,16 $\leq \mathrm{x}<6,00$ yaitu di angka 5,19 yang diartikan rata - rata responden sangat setuju dengan pernyataan ini. Pernyataan sangat setuju tersebut adalah harapan konsumen yang menginginkan produk yang aman untuk dikonsumsi, penampilan produk yang harus menggambarkan kualitas produk yang baik, fitur yang menarik serta kemasan yang dapat menjaga isi produk tetap aman dan terjaga sampai ke tangan konsumen.

\section{$>\quad$ Tanggapan Responden terhadap Minat Beli}

Tanggapan responden terhadap pernyataan secara rata - rata sangat setuju, hal ini dibuktikan nilai mean yang diperoleh pada setiap pernyaataan berada pada interval rata - rata 5,16 $\leq \mathrm{x}<6,00$ yaitu di angka 5,19 yang diartikan rata - rata responden sangat setuju dengan pernyataan yang diberikan yaitu responden/ masyarakat merasa tertarik dan bersedia membeli produk ini dimasa yang akan datang.

- Uji Normalitas

\begin{tabular}{|l|c|c|c|}
\hline & Model 1 & Model 2 & Model 3 \\
\hline Asymp Sig (2-tailed) & 0.053 & 0.054 & 0.2 \\
\hline
\end{tabular}

Hasil nilai dari ketiga model lebih besar dari nilai alpha 0,05. Maka dapat disimpulkan bahwa data di atas berdistribusi normal.

- Uji Multikolinieritas

\begin{tabular}{|c|c|c|}
\hline Variabel & Tolerance & VIF \\
\hline Kemasan & 0.027 & 37.178 \\
\hline Kualitas & 0.027 & 37.178 \\
\hline
\end{tabular}

Nilai VIF > 10 dan nilai tolerance $<0,1$ dapat dikatakan kemasan dan kualitas multikolinieritas sehingga dimungkinkan terjadinya hubungan antara kemasan dan kualitas (Model 2).

- Asumsi Heterokedastisitas

\begin{tabular}{|c|c|}
\hline Variabel & Sig. \\
\hline Kemasan & 0,0612 \\
\hline Kualitas & 0,801 \\
\hline
\end{tabular}

Kedua variabel terbebas dari masalah heteroskedastisitas, karena variabel kemasan dan kualitas memiliki nilai signifikasi > 0,05.

- Uji F

- Model $1 \mathrm{~F}(\mathrm{sig})>\mathrm{F}$ tabel atau nilai $\mathrm{F}$ sig $<0,05$ maka hubungan antara variabel independen dan dependen bersifat tidak linear. $\mathrm{F}$ tabel pada model ini adalah $\mathrm{a}=0,05$ dengan pembilang df $(\mathrm{n} 1)=\mathrm{k}-1=3-1=2$, penyebut df $(\mathrm{n} 2)=\mathrm{n}-\mathrm{k}=500-2=498$ maka diperoleh niali $\mathrm{F}$ tabel adalah 2,389.

- Model 2 nilai F hitung yang di peroleh untuk pengaruh kemasan dan kualitas terhadap minat beli lebih besar dibandingkan dengan $\mathrm{F}$ tabel dan nilai sig yaitu 0,000 lebih kecil 
dari alpa 0,05. Berdasarkan F hitung sebesar 12088,351 lebih besar dari F tabel. Maka dapat ditarik kesimpulan kemasan bersifat linier terhadap minat beli.

- Model 3 nilai F hitung yang di peroleh untuk pengaruh kemasan dan kualitas terhadap minat beli lebih besar dibandingkan dengan $\mathrm{F}$ tabel dan nilai sig yaitu 0,000 lebih kecil dari alpa 0,05. Berdasarkan F hitung sebesar 18053,016 lebih besar dari F tabel. Maka dapat ditarik kesimpulan kemasan bersifat linier terhadap kualitas.

\section{- Uji T}

- nilai t hitung untuk variabel kemasan yaitu sebesar 109,947 lebih besar dari t tabel yaitu 1,96 dan nilai sig yaitu sebesar 0,000 lebih kecil dari 0,05. Dengan ini menyatakan bahwa variabel kemasan berpengaruh secara langsung terhadap variabel minat beli tanpa adanya variabel mediator.

- Nilai t hitung untuk variabel kemasan yaitu sebesar 134,362 lebih besar dari t tabel yaitu 1,96 dan nilai sig yaitu sebesar 0,000 lebih kecil dari 0,05. Dengan ini menyatakan bahwa variabel kemasan berpengaruh secara langsung terhadap variabel kualitas.

- nilai t hitung untuk variabel kemasan yaitu sebesar 7,477 lebih besar dari t tabel yaitu 1,96 dan nilai sig yaitu sebesar 0,000 lebih kecil dari 0,05. Kemudian didapat t hitung untuk variabel kualitas yaitu sebesar 13,960 lebih besar dari t tabel yaitu 1,96 dan nilai sig yaitu sebesar 0,000 lebih kecil dari 0,05. Dengan ini menyatakan bahwa variabel kemasan berpengaruh terhadap variabel minat beli begitu juga dengan variabel kualitas berpengaruh terhadap variabel minat beli.

- Uji Causal Steps

Langkah kausal step yaitu (a) menguji regresi sederhana antara variabel kemasan terhadap minat beli secara langsung tanpa melibatkan variabel kualitas (jalur c), (b) menguji regresi sederhana antara kemasan terhadap kualitas (jalur a), (c) menguji regresi berganda kemasan dan Kualitas terhadap minat beli secara simultan (Jalur c dan b).

\begin{tabular}{|c|c|c|}
\hline Kemasan $(\mathbf{X})$ & 0,643 \\
0,000 & $\operatorname{Minat}$ Beli $(\mathbf{Y})$ \\
\hline
\end{tabular}

Regresi Sederhana Variabel X terhadap Variabel Y tanpa Variabel Mediasi

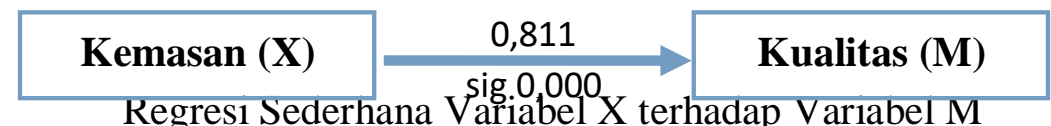

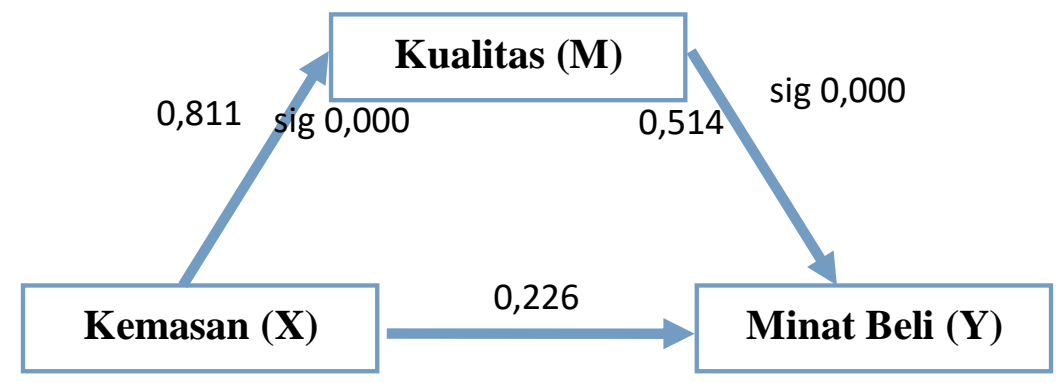

Regresi Berganda Variabel X Xig 0,000 ariabel M terhadap Variabel Y

- Pengujian Sobel Test

\begin{tabular}{|c|c|c|c|}
\hline Koefisien a & Koefisien b & Standar Eror a & Standar Eror b \\
\hline 0,811 & 0,514 & 0,006 & 0,037 \\
\hline
\end{tabular}


Didapat nilai t hitung sebesar 13,819 lebih besar dibandingkan t tabel yaitu 1,96 maka disimpulkan terjadi pengaruh mediasi secara tidak langsung antara variabel kemasan terhadap variabel minat beli melalui variabel kualitas.

\section{Hasil Pengujian Hipotesis}

- $\quad$ Hipotesis 1

Pengujian dari pengaruh langsung variabel kemasan $(\mathrm{X})$ terhadap variabel minat beli (Y) didapat nilai koefisien sebesar 0,643 dengan nilai signifikan sebesar 0,000 lebih kecil dari p value yaitu 0,05. Dengan demikian H1 diterima dalam penelitian ini bahwa variabel kemasan $(\mathrm{X})$ memiliki pengaruh yang signifikan terhadap minat beli (Y). Hal ini senada dengan Sara Kok (2014) yang menyatakan kemasan memainkan peran utama dalam menarik dan berkomunikasi dengan konsumen pada titik pembelian.

- $\quad$ Hipotesis 2

Pengujian dari pengaruh langsung variabel kemasan (X) terhadap kualitas (M) didapat nilai koefisien sebesar 0,811 , nilai signifikan sebesar $0,000<\mathrm{p}$ value yaitu 0,05 . Kemasan (X) memiliki pengaruh yang signifikan terhadap kualitas (M). Dengan demikian $\mathrm{H} 2$ diterima dalam penelitian ini bahwa variabel kemasan (X) memiliki pengaruh positif dan signifikan yang signifikan terhadap kualitas (M).

Hal ini senada dengan Shaharudin Mohd (2011) yang menyatakan kualitas produk berpengaruh signifikan terhadap minat beli.

- Hipotesis 3

Pengujian dari pengaruh variabel kualitas $(\mathrm{M})$ terhadap variabel minat beli $(\mathrm{Y})$ didapat nilai koefisien sebesar 0,514, nilai signifikan sebesar $0,000<\mathrm{p}$ value yaitu 0,05 . Kualitas (M) memiliki pengaruh yang signifikan terhadap minat beli (Y). Maka dapat disimpulkan bahwa model ini termasuk dalam mediasi parsial, dimana variabel kemasan mampu mempengaruhi secara langsung variabel minat beli maupun secara tidak langsung dengan melibatkan variabel mediasi kualitas atau dapat dikatakan bahwa kualitas dapat memediasi antara kemasan dengan minat beli.

\section{KESIMPULAN}

Kesimpulan dari penelitian ini adalah kemasan memiliki pengaruh yang signifikan terhadap minat beli kerupuk ikan tenggiri merek Legit, kemasan memiliki pengaruh yang signifikan terhadap kualitas kerupuk ikan tenggiri merek Legit, kemasan memiliki pengaruh yang signifikan terhadap minat beli yang dimediasi oleh kualitas kerupuk ikan tenggiri merek Legit.

\section{DAFTAR PUSTAKA}

Farooq, Sania. Habib, Salman. Aslam, Saira. 2015. Influence of product packaging on consumer purchase intention. International journal of economic, commerce and management. Vol III, Issue 12. Desember 2015.

Kok, Sara. 2015. Never Seen, Never Heard, Never Sold, A Study on the Influence of Product Packaging on Brand Image and Purchase Decision. Thesis. Lulea University of Technology.

Kotler P, Armstrong G. 2012. Prinsip-prinsip Pemasaran. Jilid 2. Edisi 13 Jilid 1. Jakarta: Erlangga

Kotler, P. (2000). Manajemen Pemasaran, edisi millennium. Jakarta: Prenhallindo.

Naik, Alok Kumar. 2015. Empirical Study on Packaging Factor Influencing Consumer Buying Decision in Confectionery Item. Dissertation. School of Management Nit Rourkela 
Orville C. Walker, Boyd. Harper W, Larreche, Jean Clude. 2005. Manajemen Pemasaran Suatu Pendekatan Strategis Dengan Orientasi Global. Jakarta: Erlangga.

Polyakova, Ksenia. 2013. Packaging design as a Marketing tool and Desire to purchase. Thesis. Saimaa University of Applied Science.

Suhendra. 2009. Mengemas Laba Bisnis Kemasan. Detik Finance, 10 November 2009 [Internet]. [diunduh pada 2017 November 18]. Tersedia pada: http://finance.detik.com/read/2009/11/10/091820/1238640/480/mengemas -laba-bisniskemasan 
